\title{
JUURNAL.RU
}

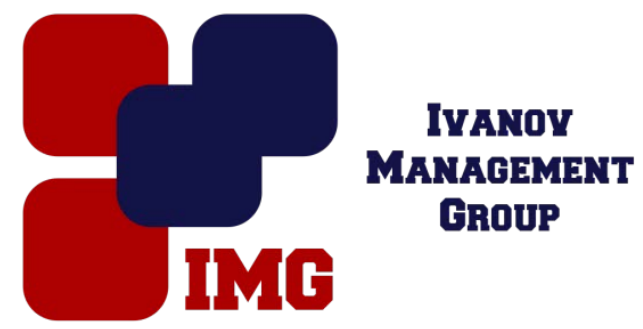

Гончарова А.В. Российская Академия Народного Хозяйства и Государственной службы при Президенте РФ Москва, Россия

doi: 10.18411/lj-28-02-2017-4-02

idsp 000001:lj-28-02-2017-4-02

\section{К вопросу о прерванных конструкциях в современной английской диалогической речи}

В последнее время все большее внимание привлекают к себе так называемые прерванные конструкции, встречающиеся в основном в диалогической речи. На материале английского языка прерванные инструкции практически почти не изучались, поэтому их исследование представляется интересным и актуальным.

В данной статье делается попытка определения лингвистического статуса прерванных конструкций и их места среди других сходных синтаксических построений на материале английского языка.

Само название "прерванная конструкция" требует разъяснения, ибо неадекватно передает суть изучаемого явления. Понятие прерванности коррелируется с понятием возобновляемости, т.е. на первый взгляд прерванная конструкция должна пониматься как такая, в которой временно останавливается, а затем возобновляется фонация, или в которой временно нарушается плавкость синтагматической цепи. И такие конструкции, действительно, наблюдаются среди прерванных, не образуя, однако, их ядра. Ядро же прерванных конструкций образуют такие, в которых фонация обрывается (а не прерывается), причем это может быть и в середине слова и после предлога. После паузы высказывание может и возобновиться, но не как продолжение прерванного, а в иной форме. В англистике такие конструкции называются более удачно - фрагментами.

Изучение прерванных конструкций связано с целым рядом проблем. Это, прежде всего, проблема порождения прерванности. Обратимся сначала к причинам появления прерванных конструкций вообще и в английском языке в частности. Ключ к решению данной проблемы дает четырехступенчатая теория порождения речевого высказывания, выдвинутая А.А.Леонтьевым, выделяющим этап мотивации высказывания, этап замысла (Плана) высказывания, этап реализации Плана и этап сопоставления реализации замысла с Планом, т.е. этап контроля.

Заметим, что этап реализации Плана может частично совпадать по времени с этапом формирования Плана - когда при реализации одного высказывания уже 
начинает планироваться новое высказывание. Этап контроля может проходить одновременно с реализацией. На этих стыках и возникают речевые формы, известные как прерванные конструкции, которые появляются в обстановке высокого эмоционального напряжения, наблюдаемого между участниками речевого акта. Следствием является сбой ритма предложения, прерывание его, что графически выражается с помощью тире или многоточия.

Разные исследователи выдвигали различные причины появления прерванности. Обобщая их, можно сказать, что существуют внутренние и внешние по отношению к говорящему причины порождения прерванности. В первом случае говорящий прерывает фонацио из-за изменений, возникших в замысле высказывания (1) или затруднений в его грамматическом или лексическом оформлении (2), например:

(1) I want to say - well, first of all forgive me for bothering you again. You'll begin to think I'm neurotic woman with a fixation. Never my dear Rachel!

Thanks. Oh I feel so unhappy about everything that's happened lately (B.P., 216).

(2) "Doctor" - said Arnold. "Yes, you see, she" - "She fell?" I suggested (B.P., $31)$.

В таком случае прерванное высказывание может возобновиться, хотя чисто механическое восстановление синтагматической цепи невозможно.

К внешним причинам порождения прерванности можно отнести вмешательство или самоустранение собеседника (3), автора (4), влияние окружающей среды (5), физическое состояние говорящего (б) и др.:

(3) "But Breadley, you didn't say that you" - "Enough, enough. How are your parents?" (B.P., 202).

"Cristian got to know a lot of Jews in America. I think that made a difference" - I stared at Francis. When you find out that somebody is Jewish they look different (B.P., 148).

(5) Bradley, don't shout. I -

The telephone rings again (B.P., 90).

(6) "Eachel - dear - nice - happy - you - so glad -"

"You can't be drunk at this hour of the morning" (B.P., 233).

Таким образом, появление прерванных предложений может быть; обусловлено как внутренними (глубинными) причинами, основанными на аритмии и нарушении операций при порождении предложения, так и внешними (поверхностными) причинами коммуникативного плана.

Теперь остановимся на вопросе определения лингвистического статуса прерванных конструкций. При этом возникают различные аспекты данной проблемы. Во-первых, мнения расходятся относительно области отнесенности данного явления. Одни ученые, как например Е.М.Галкина-Федорук, относят прерванные конструкции к области стилистики, другие, и их большинство, рассматривают их с точки зрения синтаксиса. Однако единство взглядов здесь также не наблюдается, поскольку авторы подходят к определению прерванных конструкций исходя из разных критериев. Так, А.П.Сковородников ведущим для предложения считает признак предикативности и, соответственно, делит усеченные конструкции на собственно предложения и условные предложения. Л.В.Власова также называет прерванные структуры предложениями, но относит к прерванности и смежные с ними явления. Неполноценными предложениями, неспособными делиться на члены, считает усеченные конструкция А.А.Цой. 
Очень близка к нашему пониманию статуса прерванных конструкций как предложений, соответствующих существующим моделям двусоставных предложений, концепция И.В.Артюшкова.

При отнесении рассматриваемых конструкций к предложениям мы исходам из понимания предложения Г.Г.Почепцовым, отмечающим его коммуникативную направленность, предикативность и структурность.

Анализ практического материала позволил нам выделять две структурные группы прерванных предложений, которые могут быть названы условно прерванными и фактически прерванными или фрагментами.

Прерванные (или условно прерванные предложения) по своим семантикосинтаксическим характеристикам являются полноценными предложениями с завершенными синтаксическими связями. Отличает их от обычных нормативных предложений прерывистая фонация и специфическая графическая оформленность, свидетельствующие о незаконченности выражения речевого намерения говорящего. 89).

(7) Of course she sounds like an American now - I don't want to know!" (B.P.,

(8) "Do you always - have - difficulties?" (B.P., 158).

Такие условно прерванные предложения являются языковой реализацией прерывающихся высказываний. Они являют собой скорее стилистический, а не грамматический феномен, и порождение их связано с тем, что язык и речь находятся во взаимодополнительных отношениях: в одних случаях возможности речи оказываются ограниченнее потенциальных возможностей языка, в других шире.

Анализ показывает, что фактически прерванные предложения (фрагменты) в английском языке неоднородны ни по структурной организации, ни по целенаправленности, ни по информативной наполняемости.

По своей структуре предложения-фрагменты могут соответствовать как полипредикативному (9), так и монопредикативному двусоставному предложению (10):

(9) Those who only do what's easy wile never be rewarded by (B.F., 50).

(10) "She can't have understood" -

"I think she did understand, Bradley. I'm sorry, but I think she did".

По целенаправленности предложения-фрагменты могут представлять различные функциональные типы, что отражается в различной интонационной и пунктуационной оформленности. Эти предложения могут быть повествовательными (10), вопросительными (11) и побудительными (12).

(11) "- How can you ? - she said. Oh dear - "

"She was crying now, helplessly, wet trembling wet lips" (B.P., 357).

(12) "And what did she say?"

"Do stop looking like King Lear - " "What did she say?" (B.P., 359).

Информативная наполняемость фрагментарных предложений колеблется в большом диапазоне и связана с соотношением эксплицитного и имплицитного в них.

Анализ практического материала позволил установить большое разнообразие типов фрагментарных предложений, общим признаком которых является разрыв синтагматической цепи на стыке обязательных дистрибутивных или валентностных связей между элементами. 
Во многих работах по русистике отчетливо видна тенденция расширения границ прерванных предложений. Это связано с тем, что в качестве ведущего избирается какой-либо несущественный признак прерванности. Так, Л.Д.Власова выделяет в качестве ведущего признак мелодического рисунка и на этом основании относит к прерванности явление сегментации, но исключает парцелляцию. Однако если существенным признаком прерванных предложений считать разрыв синтагматической цепи на стыке обязательных дистрибутивах или валентностных отношений между элементами, то оба типа конструкций - с сегментацией и с парцелляцией, а также и с присоединением - исключаются из числа прерванных предложений.

Нередко прерванные предложения причисляются к неполным. Так, Ш.Балли рассматривает прерванность как одно из частных проявлений эллипсиса.

Однако между неполными предложениями и предложениями-фрагментами имеются существенные различия. Во-первых, в неполных предложениях граница эксплицитного и имплицитного, как правило, совпадает с границей члена предложения (или словосочетания), в то время как в прерванных предложениях эта граница может проходить и внутри члена предложения (или словосочетания), разорванным может оказаться даже слово.

Во-вторых, в неполных предложениях опускаются только структурно необходимые его члены, и разрыв происходит на месте обязательных структурных или структурно-семантических связей, а в прерванных предложениях опускаться могут любые части предложения и разрыв, как правило, происходит на месте факультативных связей.

В-третьих, неполные и прерванные предложения различны по своей стилистической характеристике: первые имеют нейтральную стилистическую окрашенность, а вторые - стилистически окрашены. Кроме того, неполные предложения являются синтагматически или парадигматически восполнимыми, поскольку являются реализацией законченного высказывания, в то время как прерванные предложения зачастую не могут быть восстановлены, поскольку являются реализацией незавершенного высказывания.

Таким образом, прерванность предложения существенным образом отличается от смежных синтаксических явлений - процессов сегментации, парцелляции и, шире, присоединения - с одной стороны, и эллипсиса - с другой.

Принимая во внимание замечание В.Г.Адмони о том, что "одним из существенных моментов при характеристике синтаксических конструкций является установление их законченности или незаконченности", целесообразно выделить прерванные предложения, наряду с неполными, как один из вариантов реализации модели двусоставного предложения, воплощающий признак незаконченности синтаксической структуры и реализующий незаконченное высказывание.

Итак, прерванность в языке может порождаться как внутренними, так и внешними причинами. Прерванные конструкции целесообразно считать предложениями, которые могут быть названы условно прерванными и фактически прерванными.

Ведущим признаком прерванности является разрыв обязательных структурных и валентностных связей, внешне разрыв маркируется тире или многоточием. 
Прерванные предложения целесообразно считать вариантом двусоставного предложения, выделяемого по признаку законченности или незаконченности синтаксической структуры.

\section{Литература}

1. Bowman Eliz. The minor and fragmentary sentences o of a corpus of spoken English. International Journal of American Linguistics. V.32, № 3, Part 2, July, изд. 4, 2012.

2. Леонтьев А.А. Психолингвистические единицы и порождение речевого высказывания. М.: Наука, 2010.

3. См., напр.: Bowman Eliz. Op.cit., p.49; Артюшков И.В. Прерванные предложения в современном русском языке: Дис. ... канд. филол. наук. М., 2014.

4. См., напр.: Современный русский язык. Ч.2. М.: Изд-во МГУ, изд.4, 2011.

5. Сковородников А.П. Об усеченных предложениях. - РЯНШ, № 5, изд.3, 2014.

6. Власова Л.Д. Прерванные структуры в стихотворном синтаксисе А.С.Пушкина. - Науч. труды Курского пединститута, т.54. Очерки по стилистике русского языка. Вып. 2, изд. $4,2010$.

7. Цой А.А. О так называемых усеченных, ИЛИ недоговоренных предложениях. - РЯШ, изд. 3, 2011.

8. Артюшков И.В. Указ. соч.

9. См.: Иванова И.Д., Бурлакова В.В., Почепцов Г.Г. Теоретическая грамматика современного английского языка. М.: Высшая школа, изд.2, 2011.

10. Минкин Л.М. К взаимоотношению языковых и речевых тенденций. - ИЯШ, № 4, изд. 6 , 2008.

11. См.: Иванова И.П., Бурлакова В.В., Почепцов Г.Г. Указ. соч.

12. Власова Л.Д. Указ. соч.

13. Балли Ш. Общая лингвистика и вопросы французского языка. М., изд. 5, 2013.

14. Адмони В.Г. Завершенность конструкции как явление синтаксической формы. - ВЯ, № 1, изд. 3, 2014. 